\title{
Conduction defects, ventricular arrhythmias, and late death after surgical closure of ventricular septal defect
}

\author{
R S BLAKE^, E E CHUNG, H WESLEY, K A HALLIDIE-SMITH \\ From the Royal Postgraduate Medical School, London
}

SUMMARY One hundred and eighty-seven patients who had surgical closure of a ventricular septal defect between 1958 and 1975 were followed for up to 21 years. There were 17 late sudden deaths of which eight occurred in completely fit patients while nine were already under medical care. In an attempt to elucidate possible risk factors the preoperative and serial postoperative electrocardiograms of all patients were studied. Fifty-one unselected healthy follow-up patients agreed to 24 hour ambulatory monitoring. Progressive exercise testing (Bruce protocol) was carried out on 31 of them and an additional seven patients. There was a significant correlation between recorded ventricular arrhythmias and conduction defects, particularly progressive conduction defects. Transient complete heart block carried a bad prognosis and grade 3-4b ventricular arrhythmias were a major risk factor and recorded in 10 of the 17 patients who died. Long-term postoperative electrocardiographic follow-up is recommended and 24 hour ambulatory monitoring and exercise testing complement the findings of the resting electrocardiogram. The long-term treatment of survivors found to have ventricular arrhythmias must be considered.

With an incidence of about two in 1000 live births, ventricular septal defect is one of commonest congenital abnormalities affecting the heart. Reports have been published on the long-term follow-up of surgical closure of the defect. ${ }^{1-4}$ Much attention has been paid to specific aspects, especially conduction disturbances $^{5-11}$ and pulmonary vascular diseases ${ }^{12-16}$ after surgery. Very little has been written about late death, and to our knowledge no paper in the English journals deals with ventricular arrhythmia and its relation to late death.

We report a series of 187 patients who were successfully operated on by W P Cleland and $\mathrm{H} \mathrm{H}$ Bentall between 1958 and 1975 at the Hammersmith Hospital and who have been followed for one to 21 years after operation with special attention to factors relating to late deaths.

\section{Subjects and methods}

Hospital records of 187 patients, whose ventricular septal defects were closed between 1958 and 1975 and who survived for more than one year after operation

^Present address: Department of Cardiology, Tygerberg Hospital, Private Bag, Tygerberg 7505, South Africa.

Accepted for publication 9 September 1981 were reviewed. Age at operation, year of operation, sex, anatomical site and size of the defect, mode of closure, haemodynamic data, postoperative heart failure, and infective endocarditis were noted and tabulated. The clinical status of survivors was determined either by direct contact with each patient or by questionnaires sent to the patients or their attending physicians.

Standard 12 lead electrocardiograms recorded preoperatively, postoperatively (period in hospital after surgery), and during the follow-up period were analysed and compared for the presence of arrhythmias, conduction disturbances, and mean frontal plane QRS axis. Left axis deviation was diagnosed when the mean frontal plane QRS axis was beyond $-30^{\circ}$. Right bundle-branch block was considered present when the QRS interval in the right precordial leads exceeded $120 \mathrm{~ms}$ with a definite terminal delay. Ventricular ectopic activity found on routine electrocardiograms was graded as outlined in Table 1.

Twenty-four hour outpatient ambulatory electrocardiographic monitoring was performed on 51 unselected patients with the Oxford Medilog cassette recording system. Recordings were analysed using a Reynolds High Speed Pathfinder analyser. Ventricular arrhythmias were graded as outlined in Table 1 using a modification of the Lown criteria. ${ }^{17}$ Subjec- 
Table 1 Grading of ventricular arrhythmias

\begin{tabular}{|c|c|c|c|}
\hline Grade & Routine electrocardiogram & $\begin{array}{l}24 \text { hour electrocardiographic } \\
\text { monitoring }\end{array}$ & Exercise test \\
\hline $\mathbf{0}$ & No ventricular extrasystoles & No ventricular extrasystoles & No ventricular extrasystoles \\
\hline 1 & $\begin{array}{l}\text { One ventricular extrasystole in less than } \\
30 \% \text { of available electrocardiograms }\end{array}$ & $\begin{array}{l}\text { Occasional ventricular extrasystoles but no } \\
\text { more than } 30 \text { in any hour of monitoring }\end{array}$ & One ventricular extrasystole per minute \\
\hline 2 & $\begin{array}{l}\text { One ventricular extrasystole in less than } \\
30 \% \text { of available electrocardiograms }\end{array}$ & $\begin{array}{l}\text { More than } 30 \text { ventricular extrasystoles in } \\
\text { any hour of monitoring }\end{array}$ & Two ventricular extrasystoles per minute \\
\hline 3 & $\begin{array}{l}\text { Multiform ventricular extrasystoles in } \\
\text { addition to two }\end{array}$ & Multiform ventricular extrasystoles & Multiform ventricular extrasystoles \\
\hline $4 a$ & Couplets in addition to two & Couplets & Couplets \\
\hline $4 b$ & $\begin{array}{l}\text { Ventricular tachycardia (salvoes of } \\
\text { three or more ventricular extrasystoles) }\end{array}$ & Ventricular tachycardia & Ventricular tachycardia \\
\hline
\end{tabular}

tive maximal exercise testing was done on 38 unselected patients, 31 of whom also had 24 hour ambulatory electrocardiographic monitoring.

The exercise tests were performed in accordance with the Bruce protocol ${ }^{18}$ on a motorised treadmill. The electrocardiogram, using Frank orthogonal leads (XYZ), was displayed on an oscilloscope and visually observed for rate and rhythm for at least 10 minutes before the exercise procedure. All arrhythmias seen during this period were recorded. During, and for five minutes after exercise, a standard electrocardiographic strip chart recorder continuously recorded these three leads. Indirect blood pressure determinations were done before and immediately after exercise. In the absence of disabling fatigue, dyspnoea, angina pectoris, or major ventricular arrhythmia (sustained ventricular tachycardia or ventricular fibrillation), the patients were encouraged to continue for as long as possible. Grading of ventricular arrhythmias was performed using the criteria of Antman et al. ${ }^{19}$ as outlined in Table 1.

Statistical analyses were done using the $\chi^{2}$ test.

\section{Results}

Of the 187 patients reported here, 102 were male and 85 female. There were 147 children whose ages ranged from 2 to 16 years. The mean age at operation was 12.6 years, range two to 44 years. The mean follow-up period was 11 years, with a range of one to 21 years. There were 17 late deaths one to 21 years after operation.

The defect was considered "large" in 167 patients and "small" ( $<1 \mathrm{~cm})$ in 20 patients. The defects were membranous in 134 patients, infundibular in 20 patients, muscular in five, in the inflow septum in eight, a Gerbode type defect in 13, and multiple in seven. The defect was patched in 95 patients and closed by sutures alone in 92 .

\section{ASSOCIATED DEFECTS AND RESIDUAL LESIONS} In addition to closure of the ventricular septal defect, 38 patients, with gradients ranging from 20 to
$60 \mathrm{mmHg}$ across the right ventricular outflow tract, had resection of infundibular muscle. Three patients had atrial septal defects closed and eight had a persistent ductus arteriosus ligated. Nineteen patients had associated aortic regurgitation. The defects in the latter patients were membranous in nine, infundibular in nine, and a left ventricular to right atrial shunt in one.

Three of them had a sinus of Valsalva fistula to the right ventricle and three had small perforations of one of the aortic cusps. All of these were closed during surgery. Thirteen patients had a right or noncoronary cusp prolapsing through the ventricular septal defect, requiring valvuloplasty in all.

The aortic regurgitation was considered mild in 10 patients, moderate in five, and severe in four. Fifteen of these patients still had aortic regurgitation after surgery. Additionally, eight patients who did not have aortic regurgitation preoperatively, developed it postoperatively, making the total with postoperative aortic regurgitation 23 . In the majority (15) the postoperative aortic regurgitation was mild to moderate and remained stable during the follow-up period. Two of those, though completely asymptomatic, died unexpectedly three and 15 years after operation. In both there was reason to believe that death resulted from complete heart block.

In eight patients aortic regurgitation was progressive with left heart failure. Five of these had one or more episodes of infective endocarditis. One of them died before valve replacement could be done and three others two weeks to six months after aortic valve replacement. One is alive and asymptomatic after aortic valve replacement. Thus, a total of seven deaths occurred in the group with postoperative aortic regurgitation, four of whom had infective endocarditis as well.

On clinical grounds 43 patients were thought to have signs of residual ventricular septal defect after operation, five associated with residual aortic regurgitation and two with mitral regurgitation. In 37 the residual defect was considered insignificant, but in six it required reclosure of the defect. 


\section{ENDOCARDITIS}

During the follow-up period, 10 patients had one or more episodes of infective endocarditis. Four of these had residual ventricular septal defect, four had aortic regurgitation, and one had ventricular septal defect and aortic regurgitation. The remaining patient is of interest as he had well documented, culture positive, infective endocarditis without signs of any residual lesions.

\section{MYOCARDIAL INFARCTION}

Four patients had myocardial infarctions. Two of them had residual aortic regurgitation and one residual ventricular septal defect, all three requiring reoperation. In one the infarction followed the original operation and in two it followed reoperation. The remaining patient had pulmonary hypertension with no residual lesions and had a myocardial infarction 19 years after operation at the age of 26 . All four died.

\section{HEART FAILURE}

Nineteen patients were treated for left heart failure during the follow-up period. One of them had progressive pulmonary hypertension and myocardial infarction, one was dignosed as peripartum cardiomyopathy, one had progressive pulmonary hypertension only, and the remaining 16 all had residual ventricular septal defect and/or aortic regurgitation complicated by a myocardial infarction in one and infective endocarditis in seven. Eight of the patients who had heart failure and four who had infective endocarditis during the follow-up period died.

\section{HAEMODYNAMICS}

One hundred and three patients had preoperative systolic pulmonary artery pressures above $40 \mathrm{mmHg}$. Table 2 summarises the systolic pulmonary artery pressure:systemic artery pressure ratio, and Table 3 the pulmonary arteriolar resistance in these patients.

There were 12 late deaths in this group (cases 1,5 , $6,7,8,9,11,12,13,14,16,17$, Table 4) but only three of them (cases $1,7,9$ ) had progressive pulmonary vascular disease and their deaths were largely the result of this, though one also had complete heart block (case 9) and one had a myocardial infarction and serious ventricular arrhythmias (case 7).

Patients with raised pulmonary artery pressure and resistance did not have a significantly increased incidence of conduction disturbances or ventricular arrhythmias. The functional status of patients with pulmonary vascular disease has been previously reported. ${ }^{12} 13$

\section{CONDUCTION PATTERNS}

Conduction disturbances were common after closure of a ventricular septal defect. In all our patients the defect was closed via a ventriculotomy so that comparison with other surgical techniques was not possible.

Fig. 1 summarises the various conduction patterns found preoperatively, postoperatively, and on the last available electrocardiogram during the follow-up period. The figures in brackets are the numbers of late deaths.

Preoperatively there were 10 patients with left axis deviation and 12 with right bundle-branch block. Two of these had left axis deviation plus right bundle-branch block and one had right bundlebranch block, left axis deviation, and first degree atrioventricular block.

Postoperatively there was a total of $105(56 \%)$ patients with right bundle-branch block and 26 (14\%) with left axis deviation alone or in combination. Subsequently, a further 14 developed right bundlebranch block and 16 left axis deviation. This is partly accounted for by 14 of the patients who had transient second degree atrioventricular block or complete heart block postoperatively. Three of these were left with left axis deviation, right bundle-branch block, and first degree atrioventricular block, four with left axis deviation plus right bundle-branch block, three with first degree atrioventricular block and right bundle-branch block, and four with right bundlebranch block alone. There remains a group of nine patients who developed left axis deviation one to 10 years postoperatively, having previously had normal

Table 2 Preoperative systolic pulmonary artery: systemic artery pressure ratio in 103 patients with systolic pulmonary artery pressure $>40 \mathrm{mmHg}$

\begin{tabular}{llllllllll}
\hline Pressure ratio & 0.3 & 0.4 & 0.5 & 0.6 & 0.7 & 0.8 & 0.9 & 1 \\
Number & 11 & 18 & 12 & 15 & 7 & 11 & 8 & 19 & 2 \\
\hline
\end{tabular}

Table 3 Preoperative pulmonary arteriolar resistance in 103 patients with systolic pulmonary artery pressure $>40 \mathrm{mmHg}$

\begin{tabular}{lllllllll}
\hline Pulmonary arteriolar & & & & & & \\
resistance & 2 & $2 \cdot 1-3$ & $3 \cdot 1-4$ & $4 \cdot 1-5$ & $5 \cdot 1-7$ & $7 \cdot 1-10$ & $10 \cdot 1-15$ & $>15$ \\
No. & 24 & 14 & 10 & 8 & 7 & 23 & 9 & 5 \\
\hline
\end{tabular}




\begin{tabular}{|c|c|c|c|c|c|c|c|c|c|}
\hline $\begin{array}{l}\text { Normal } \\
\text { conduction }\end{array}$ & LAD & RBBB & $1^{\circ} \mathrm{AVB}$ & $2^{\circ} \mathrm{AVB}$ & $\mathrm{TCHB}$ & $\mathrm{PCBH}$ & $\begin{array}{l}\text { LAD } \\
+ \\
\text { RBBB }\end{array}$ & $\begin{array}{c}\text { LAD } \\
+ \\
{ }^{+} \\
1^{+} \\
1^{+} \\
\text {AVB }\end{array}$ & $\begin{array}{c}1^{\circ} \mathrm{AVB} \\
+ \\
\text { RBBB }\end{array}$ \\
\hline
\end{tabular}

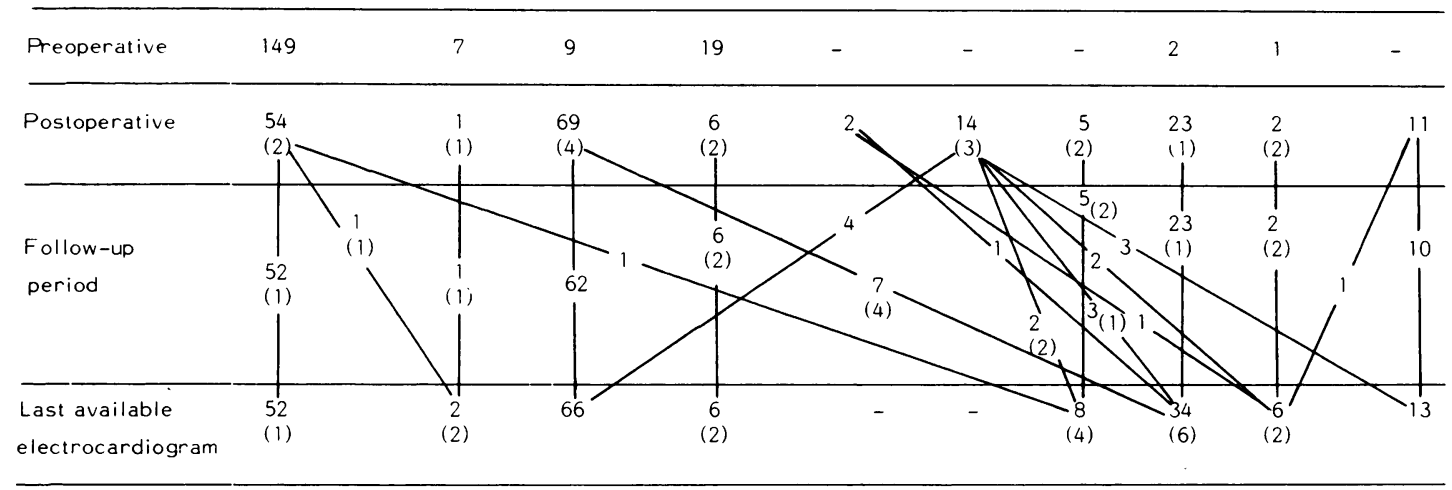

\footnotetext{
Figures in brackets indicate number of deaths.

Abbreviations: $L A D=$ left axis deviation; $R B B B=$ right bundle-branch block; $A V B=$ atrioventricular block;

$\mathrm{TCHB}=$ temporary complete heart block; $\mathrm{PCHB}=$ permanent complete heart block.
}

Fig. 1 Conduction patterns on preoperative, postoperative, and last available electrocardiogram.

conduction in one, right bundle-branch block alone in seven, and first degree atrioventricular block and right bundle-branch block in one. Five of these patients with progressive conduction defect died (cases $1,5,7,13$, and 17). Two patients with transient complete heart block postoperatively developed complete heart block again, one (case 9) 13 years after operation and the other (case 15) developed transient complete heart block again 15 years later during recatheterisation. Both these patients subsequently died. One patients with normal conduction postoperatively later developed first degree atrioventricular block and 15 years postoperatively he had a few fainting spells. During one of these an electrocardiogram was done which showed a transient complete heart block. He was Holter monitored and, during the 24 hours, he had normal conduction alternating with first, second, and third degree atrioventricular block. He has had a pacemaker implanted and is now free of symptoms.

\section{RHYTHM DISTURBANCES}

Table 5 gives a detailed analysis of the ventricular arrhythmias detected on routine electrocardiogram during the follow-up period in the whole group and correlates it with the conduction pattern in each patient. The number of late deaths is indicated by the bottom figure in brackets in each column. One hundred and forty-eight patients had no ventricular arrhythmias. Six of these patients died. Three of them had complete heart block (cases 14, 15, and 16, Table 4), one had a first degree atrioventricular block
Table 5 Ventricular arrhythmia (grade) vs conduction on routine electrocardiograms during follow-up period

\begin{tabular}{|c|c|c|c|c|c|c|c|}
\hline \multirow[t]{2}{*}{ Conduction } & \multicolumn{7}{|c|}{ Ventricular arrhythmia } \\
\hline & 0 & 1 & 2 & 3 & $4 a$ & $4 b$ & Total \\
\hline Normal & $\begin{array}{l}48 \\
(1)\end{array}$ & 1 & 1 & 1 & & & $\begin{array}{l}52 \\
(1)\end{array}$ \\
\hline LAD & & & & & & $\begin{array}{c}2 \\
(2)\end{array}$ & $\begin{array}{c}2 \\
(2)\end{array}$ \\
\hline RBBB & 53 & 8 & 4 & 1 & & & 66 \\
\hline $1^{\circ} \mathrm{AV}$ block & 4 & & & 1 & & 1 & 6 \\
\hline $\begin{array}{l}1^{\circ} \mathrm{AV} \text { block } \\
+\mathrm{RBBB}\end{array}$ & 9 & 1 & & 3 & & & $\begin{array}{l}13 \\
(0)\end{array}$ \\
\hline $\mathrm{LAD}+\mathrm{RBBB}$ & $\begin{array}{l}26 \\
(1)\end{array}$ & 2 & 1 & $\stackrel{1}{(1)}$ & $\begin{array}{c}3 \\
(3)\end{array}$ & $\begin{array}{l}1 \\
(1)\end{array}$ & $\begin{array}{l}34 \\
(6)\end{array}$ \\
\hline $\begin{array}{l}1^{\circ} \mathrm{X} \text { AV block }+ \\
\text { LAD + RBBB }\end{array}$ & 2 & $\begin{array}{l}1 \\
(1)\end{array}$ & & 1 & 1 & (1) & $\begin{array}{l}6 \\
(2)\end{array}$ \\
\hline CHB & $\begin{array}{l}6 \\
(3)\end{array}$ & & 1 & (1) & & & $\begin{array}{l}8 \\
(4)\end{array}$ \\
\hline Total & $\begin{array}{r}148 \\
(6)\end{array}$ & $\begin{array}{l}14 \\
(1)\end{array}$ & $\begin{array}{c}7 \\
(0)\end{array}$ & $\begin{array}{c}9 \\
(3)\end{array}$ & $\begin{array}{c}4 \\
(3)\end{array}$ & $\begin{array}{c}5 \\
(4)\end{array}$ & $\begin{array}{l}187 \\
\text { (17) }\end{array}$ \\
\hline
\end{tabular}

Figures in brackets indicate number of late deaths.

Abbreviations: Fig. 1. Grading: As in Table 1.

(case 2), and two had uncomplicated sinus rhythm (cases 1 and 11).

Fourteen patients had grade 1 ventricular arrhythmia. Only one of these patients (case 8), who also had left axis deviation, right bundle-branch block, and first degree atrioventricular block, died.

Seven patients had grade 2 ventricular arrhythmia. There were no late deaths in this group.

Nine patients had grade 3 ventricular arrhythmia, 
three of whom died. One of the deaths had an associated first degree atrioventricular block (case 4), one a complete heart block (case 9), and one had left axis deviation plus right bundle-branch block (case 17).

Four patients had grade 4a ventricular arrhythmia. Three of these died (cases 7, 10, and 12); all three also had left axis deviation plus right bundle-branch block.

Five patients had grade $4 \mathrm{~b}$ ventricular arrhythmia, four of whom died. Two of these (cases 3 and 5) had left axis deviation and two (cases 6 and 13) had left axis deviation plus right bundle-branch block.

Eleven patients had supraventricular arrhythmias during the follow-up period. In six this was established atrial fibrillation, while five others had paroxysmal atrial fibrillation or atrial tachycardia. Five of the patients with supraventricular arrhythmias died, but all had ventricular arrhythmias as well. Three had grade $4 \mathrm{~b}$, one had grade $4 a$, and one had grade 3 ventricular arrhythmia.

Patients with conduction defects had a significantly increased incidence of ventricular arrhythmias of all grades $(\mathrm{p}<0.003)$.

\section{LATE DEATHS}

Seventeen patients died one to 21 years after operation. They were all operated upon before 1968 . Table 4 summarizes the clinical, electrocardiographic, and haemodynamic findings in these patients.

In five (cases $3,6,8,11$, and 13) the immediate cause of death was documented as ventricular fibrillation in hospital. In nine more the terminal events strongly suggested death from arrhythmia. The remaining three patients died of progressive pulmonary vascular disease (case 1), intraperitoneal haemorrhage after aortic valve replacement (case 4), and during surgery for aortic valve replacement (case 2).

Cases 1 and 2, who died from causes other than arrhythmias, did not have any documented ventricular arrhythmias, while case 4 had grade 3 ventricular arrhythmia.

Only one of the patients who died of arrhythmia (case 11) had normal conduction and no ventricular arrhythmias documented during the follow-up period, but there was only one electrocardiogram available for analysis. The remaining 13 arrhythmic deaths all had ventricular arrhythmias and/or conduction defects during the follow-up period. (This has already been discussed.) The risk of late death was significantly increased by the presence of grade $3-4 b$ ventricular arrhythmia $(p<0.001)$.

On clinical grounds the late deaths could be divided into a group of eight patients in whom death was sudden and unexpected, and nine in whom death was not unexpected.

\section{EXPECTED LATE DEATHS}

(cases 1, 2, 3, 4, 5, 6, 7, 8, 9, Table 4)

These patients had a mean age of 25.4 years at operation (range five to 41 years).

Three had progressive pulmonary vascular disease and falling cardiac output (cases 1,9, and 7) complicated in case 9 by residual ventricular septal defect and complete heart block and in case 7 by grade $4 b$ ventricular arrhythmia, left axis deviation and right bundle-branch block, and a myocardial infarction. They died respectively 15, 16, and 21 years after operation.

Four patients (cases 3, 4, 5, and 6) had postoperative aortic regurgitation, one had aortic regurgitation and residual ventricular septal defect (patient 2), and two had residual ventricular septal defect (patients 8 and 9). In five of these the residual lesions required reoperation (cases $2,3,4,5$, and 8 ). Three of these patients (cases 4, 5, and 8) also had myocardial infarctions. Case 5 had an extensive anterior infarction after the original operation. He had repeated attacks of angina pectoris after discharge, increasing aortic regurgitation and left heart failure necessitating aortic valve replacement three years later. After this operation he had repeated classical Adams-Stokes attacks and died during one of them six months later. Cases 4 and 8 had myocardial infarction after reoperation for aortic valve replacement (case 4) and closure of residual ventricular septal defect (case 8). Both died in hospital within one month of operation. Four of the late deaths with residual lesions were also treated for infective endocarditis (cases 3, 4, 5, and 6) during the follow-up period.

\section{SUDDEN UNEXPECTED DEATHS}

The patients in this group had a mean age of 13.7 at operation. Only one (case 17) had signs of mild heart failure during the last four years of follow-up. After operation he had atrial fibrillation and right bundlebranch block. He gradually developed left axis deviation over the following six years. He also had grade 3 ventricular arrhythmia and died suddenly at home nine years after operation. He complained of palpitation two weeks before death.

Four patients developed complete heart block after operation (cases 12, 14, 15, and 16). In two the block was permanent. One of them (case 14) developed mild aortic regurgitation two weeks after operation and died suddenly three years after operation after a mild respiratory infection. The other patient (case 16) with permanent complete heart block died suddenly at home one year after operation. He had pulmonary hypertension and raised pulmonary arteriolar resistance but was completely asymptomatic. Case 15 had a small ventricular septal defect and mild aortic regurgitation. He was asymptomatic but redeveloped 
transient complete heart block 15 years after closure of his ventricular septal defect during a catheterisation procedure and died suddenly one month later at home.

The other patient with transient postoperative complete heart block (case 12) had a small residual ventricular septal defect but was asymptomatic. His follow-up electrocardiogram showed right bundlebranch block, left axis deviation, and first degree atrioventricular block complicated by grade $4 \mathrm{a}$ ventricular arrhythmia. He died suddenly at home. Case 11 had normal conduction and no ventricular arrhythmias noted during follow-up. He was asymptomatic and died of documented ventricular fibrillation during anaesthesia for a fractured forearm one year after operation.

Case 13 had frequent attacks of paroxysmal supraventricular tachycardia. He also had left axis deviation, right bundle-branch block, and grade $4 \mathrm{~b}$ ventricular arrhythmia and died of ventricular fibrillation during anaesthesia for a dental extraction three years after closure of his ventricular septal defect.

Finally, case 10 had a small residual ventricular septal defect but was completely asymptomatic. He had left axis deviation, right bundle-branch block, and grade $4 \mathrm{a}$ ventricular arrhythmia. He died suddenly at home, presumably from a ventricular tachyarrhythmia.

\section{TWENTY FOUR HOUR AMBULATORY}

ELECTROCARDIOGRAPHIC MONITORING

Continuous 24 hour monitoring was performed on 51 unselected patients 10 to 20 years (mean 14 years) after operation. Table 6 correlates the highest grade of ventricular arrhythmia with the conduction pattern on the 12 lead electrocardiogram. Fig. 2 compares the ventricular arrhythmias detected on continuous 24 hour monitoring with those found on the routine electrocardiograms.

Nineteen patients had ventricular arrhythmias during the 24 hours of monitoring. In eight of them, the arrhythmia was Lown grade 3-4b. All the patients with ventricular arrhythmia had conduction disturbances. Two of the patients with grade 4a ventricular arrhythmia have subsequently died, one of them unexpectedly. Three patients had progressive conduction defect. All of them had ventricular arrhythmias and one died. Thirty-two patients had no ventricular arrhythmias, 16 of them had normal conduction, and 16 had conduction disturbances.

\section{EXERCISE TEST}

Exercise testing was done on $\mathbf{3 8}$ unselected patients. Table 7 correlates the ventricular arrhythmias according to the Antman criteria with the conduction pattern on the 12 lead electrocardiogram. Fig. 3 compares the higest grade of ventricular arrhythmia found on exercise with that on continuous 24 hour monitoring in the 31 patients who had both tests.

Sixteen patients had ventricular arrhythmias during or immediately after exercise, five of them grade 3 or

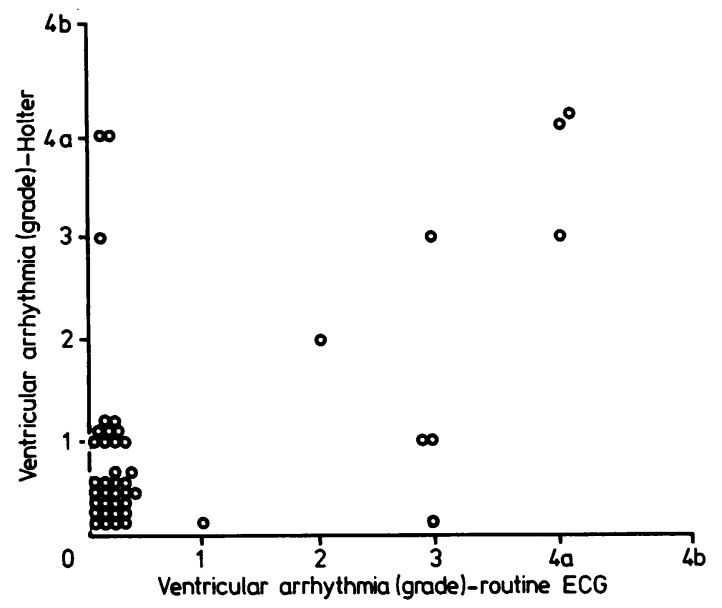

Fig. 2 Ventricular arrhythmia-24 hour continuous electrocardiographic monitoring versus routine electrocardiogram.

Table 624 hour ambulatory electrocardiographic monitoring: ventricular arrhythmia (grade) vs conduction

\begin{tabular}{|c|c|c|c|c|c|c|c|}
\hline \multirow[t]{2}{*}{ Grade } & \multicolumn{7}{|c|}{ Conduction } \\
\hline & Normal & $R B B B$ & $\begin{array}{l}L A D+ \\
R B B B\end{array}$ & $\begin{array}{l}L A D+I^{\circ} A V \\
\text { block }+R B B B\end{array}$ & $P C D$ & $C H B$ & Total \\
\hline $\begin{array}{l}0 \\
1 \\
2 \\
3 \\
4 a \\
4 b \\
\text { Total }\end{array}$ & $\frac{16}{-} \frac{-}{16}$ & $\begin{array}{r}7 \\
\frac{3}{1} \\
\frac{2}{13}\end{array}$ & $\begin{array}{r}8 \\
5 \\
1 \\
1 \\
1 \\
16\end{array}$ & $\frac{-}{\frac{1}{1}} \frac{}{1}$ & $\begin{array}{l}\frac{1}{1} \\
\frac{1}{1} \\
\frac{1}{3}\end{array}$ & $\begin{array}{l}1 \\
\frac{1}{-} \\
\frac{-}{2}\end{array}$ & $\begin{array}{r}32 \\
10 \\
1 \\
3 \\
4 \\
1 \\
51\end{array}$ \\
\hline
\end{tabular}

Abbreviation: PCD, progressive conduction defect.

Other abbreviations as in Fig. 1. 
Table 7 Exercise test: ventricular arrhythmia (grade) vs conduction

\begin{tabular}{|c|c|c|c|c|c|c|}
\hline \multirow[t]{2}{*}{ Grade } & \multicolumn{6}{|c|}{ Conduction } \\
\hline & Normal & $R B B B$ & $L A D+R B B B$ & $\begin{array}{l}L A D+1^{\circ} A V \text { block } \\
+R B B B\end{array}$ & $C H B$ & Total \\
\hline $\begin{array}{l}0 \\
1 \\
2 \\
3 \\
4 a \\
4 \mathrm{~b}\end{array}$ & $\begin{array}{r}9 \\
1 \\
- \\
- \\
-\end{array}$ & $\frac{6}{2} \frac{2}{1}$ & $\begin{array}{r}6 \\
3 \\
3 \\
1 \\
-1\end{array}$ & $\begin{array}{l}- \\
\frac{1}{-} \\
-\end{array}$ & $\begin{array}{l}1 \\
\frac{1}{-} \\
- \\
-\end{array}$ & $\begin{array}{r}22 \\
7 \\
4 \\
3 \\
0 \\
2\end{array}$ \\
\hline Total & 10 & 11 & 14 & 1 & 2 & 38 \\
\hline
\end{tabular}

Abbreviations as in Fig. 1.

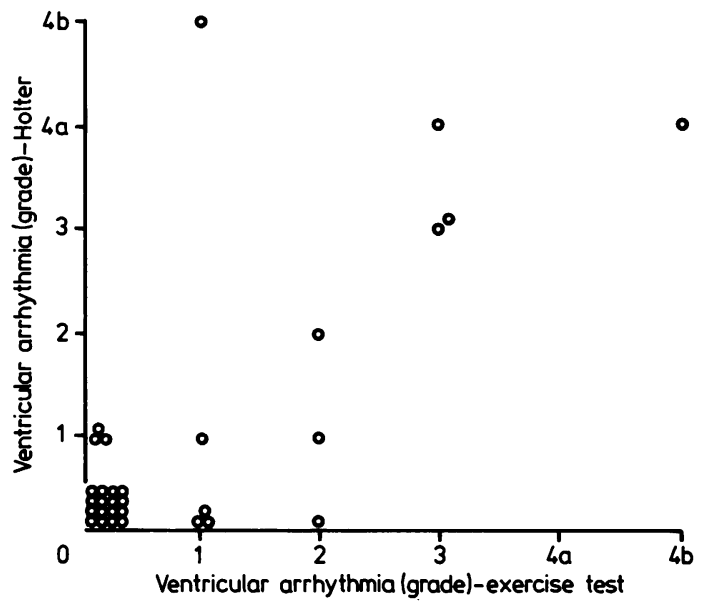

Fig. 3 Ventricular arrhythmia-24 hour continuous electrocardiographic monitoring versus exercise.

higher. Fifteen of the patients with ventricular arrhythmia had conduction disturbances as well.

Twenty-two patients had no ventricular arrhythmias on exercise. Nine of them had normal conduction and 13 had conduction disturbances.

\section{Discussion}

Conduction disturbances after surgical closure of ventricular septal defect has been recognised as the most common complication of this operation. ${ }^{5681011}$ Right bundle-branch block has been reported to occur in 31 to $70 \%$ of cases repaired via a ventriculotomy, 5692021 and left axis deviation in six to $47 \% 691022$ of cases. Sixty-three per cent of our patients had right bundle-branch block and $22.4 \%$ had left axis deviation on their last available electrocardiogram. If we omit the 10 patients who already had left axis deviation preoperatively, $17 \cdot 1 \%$ acquired left axis deviation as a result of operation. We had 9 patients who developed left axis deviation one to 10 years after operation. Five $(55.6 \%)$ of these patients with progressive conduction defect died, compared with the four late deaths $(15.3 \%)$ in the group of 26 patients who already had left axis deviation postoperatively. To our knowledge this has not been reported previously. Quattlebaum et al. ${ }^{22}$ state that $56 \%$ of their patients who had right bundle-branch block and left axis deviation developed the left axis deviation one to seven years after correction of tetralogy of Fallot, but they do not correlate this with sudden late death.

Concern about the possible late development of complete heart block in patients with left axis deviation and right bundle-branch block has been expressed. ${ }^{5611}$ Downing et al. ${ }^{10}$ believe that this combination does not carry a bad prognosis in children but contend that the ultimate prognosis is undetermined. Wolff $e t$ al. ${ }^{24}$ and Godman et al. ${ }^{11}$ found a high percentage of patients developing late complete heart block had this combination previously. Godman suggests that the patients most likely to develop late complete heart block are those who have transient complete heart block postoperatively and who have left axis deviation and right bundle-branch block on return to sinus rhythm.

Our study lends some support to this view. Three of our patients developed late complete heart block. Two of them had transient complete heart block postoperatively and were left with left axis deviation and right bundle-branch block. The remaining patient had normal conduction and developed complete heart block 15 years after operation. Complete heart block is relatively common after operation 268922 but is usually a transient phenomenon. ${ }^{2822}$

A high mortality rate of up to $57 \%$ has been reported for patients with permanent complete heart block. ${ }^{2}$ Fourteen of our patients had transient complete heart block postoperatively, with three deaths (21\%). Five patients had postoperative complete heart block that persisted, two (40\%) of whom died. There were 20 patients, including the patient who developed complete heart block for the first time 15 years after operation, who had complete heart block at some 
stage, with five late deaths (25\%).

In the light of our findings, late sudden death in patients with transient or permanent complete heart block after surgical repair of ventricular septal defect should not be unexpected. Implantation of permanent pacemaker should be considered in all cases.

Much has been written about the cause of the various conduction defects of surgical closure of ventricular septal defect ${ }^{5} 61020212325-27$. It has been ascribed to the ventriculotomy, 52526 to direct trauma to the conducting tissue by the placement of sutures around the defect, ${ }^{62127}$ or to the resection of infundibular muscle in cases where this is required. ${ }^{28}$ Our study does not throw new light on this problem, but we tend to agree with Okoroma et al. ${ }^{20}$ and Downing et al. ${ }^{10}$ that all these mechanisms can produce conduction disturbances in their own right.

James et al. ${ }^{29}$ and Rosing et al. ${ }^{30}$ considered ventricular arrhythmias to be a more important cause of sudden death than complete heart block after correction of tetralogy of Fallot. Our findings strongly support those of Wolff et al. ${ }^{24}$ and Quattlebaum et al. ${ }^{22}$ who found a significant association between ventricular arrhythmias, conduction defects, and sudden death during the long-term follow-up after surgical correction of tetralogy of Fallot.

On routine electrocardiograms, $39(20.8 \%)$ had ventricular arrhythmias of all grades during the follow-up period. Eleven of these (28\%) died, 10 of them having grade 3-4b ventricular arrhythmias.

There was also a striking correlation between conduction defects and ventricular arrhythmias $(p<0.003)$. Of the 52 patients with normal conduction during the follow-up period, four $(7 \cdot 7 \%)$ had ventricular arrhythmias of all grades, while $26 \%$ of the 135 patients who had any form of conduction disturbance had ventricular arrhythmias detected on their routine electrocardiograms. Of the patients with progressive conduction defects, $66 \%$ had ventricular arrhythmias.

On continuous 24 hour monitoring not one of the 14 patients with normal conduction had any ventricular arrhythmias, while $53 \%$ of the patients with conduction defects had ventricular arrhythmias during the 24 hour period of monitoring. This is statistically significant $(p<0.001)$. The overall incidence of ventricular arrhythmias detected on continuous 24 hour monitoring was $37 \cdot 3 \%$. Deanfield et al., ${ }^{31}$ reporting a similar study on postoperative tetralogy of Fallot, found that $80 \%$ of patients with progressive conduction defects had ventricular arrhythmias. We could only monitor three patients with progressive conduction defects, and it is of interest that they all had ventricular arrhythmias and that one of these has since died, but the numbers involved are too small to make any firm conclusions.
On exercise testing only one of 10 patients (10\%) with normal conduction had ventricular arrhythmias, while 15 of the 28 patients $(53.6 \%)$ with conduction defects had ventricular arrhythmias $(p<0.02)$. In all, $39.5 \%$ of patients had ventricular arrhythmias on exercise. The incidence of ventricular arrhythmias found in our patients with continuous 24 hour monitoring and exercise testing is considerably greater than that found in similar studies of comparable subjects without heart disease. ${ }^{32}$ This significant association of ventricular arrhythmias with conduction disturbances, particularly with progressive conduction defects, suggests that the same mechanism is responsible for both. Deanfield et al. ${ }^{31}$ speculated that this may be the result of granulomata induced by suturing. Wolff et al. ${ }^{24}$ suggested that the development of complete heart block with bradycardia makes the heart more vulnerable to ventricular arrhythmias. Our study does not support this, as none of our patients who had ventricular arrhythmias detected by any of the three methods used had complete heart block at the time that their ventricular arrhythmias occurred, though this may have been the terminal factor in some of our patients who died late.

In the individual patient, there was not a good correlation of the grade of ventricular ectopic activity detected by the three methods we used. All three methods adjunctively disclosed more ventricular ectopy than any method alone.

Although the prognostic value of ventricular arrhythmias detected with continuous 24 hour electrocardiographic monitoring and exercise testing remains to be determined, two of the patients with grade $4 \mathrm{a}$ ventricular arrhythmia on continuous 24 hour monitoring have since died, one of them unexpectedly. These two patients did not have an exercise test, but both had grade 4a ventricular arrhythmia on their routine electrocardiograms.

The association of ventricular septal defect and aortic regurgitation is well recognised, with a reported incidence of 3 to $7 \% .{ }^{33} 34$ Postoperative aortic regurgitation worsened the prognosis considerably, with seven late deaths in 23 cases. In common with other workers we found an increased risk of infective endocarditis in patients with residual aortic regurgitation. Four of the five expected deaths with aortic regurgitation had had infective endocarditis during the follow-up period. Other workers have found that, in the majority of patients with residual aortic regurgitation, the regurgitation remains stable after operation. ${ }^{34}$ In 15 of our 23 patients with postoperative aortic regurgitation, the regurgitation was mild and remained stable. Five of the eight patients in whom the aortic regurgitation was progressive had infective endocarditis contributing to this progression.

Finally, it should be noted that great improvement 
in surgical technique and myocardial protection during operation has occurred in recent years. Since all our late deaths were operated on before 1968 similar series in future should yield better results.

\section{Conclusions}

There is a significant incidence of unexpected sudden death up to 21 years after surgical closure of ventricular septal defect and a high percentage of patients develop conduction disturbances after operation. Especially important are those who develop left axis deviation during the follow-up period, as they have a high mortality rate. Complete heart block during the follow-up period has a grave prognosis. Ventricular arrhythmias are common during the follow-up period. they occur significantly more frequently in patients with conduction disturbances, and grades 3 to $4 \mathrm{~b}$ particularly are reliable predictors of late death. The death in two patients as a result of ventricular fibrillation during anaesthesia for minor surgery suggests that anaesthesia after repair of ventricular septal defect should be given only in centres where full and immediate resuscitative facilities are available. The prognostic value of exercise testing and 24 hour ambulatory electrocardiographic monitoring has not been established after closure of ventricular septal defect, but, in view of the importance of ventricular arrhythmias, we strongly advocate that these tests should be done serially on all patients.

It remains to be proved that treatment of ventricular arrhythmias will prevent sudden death, but the evidence suggests that preventative treatment should be arranged, especially in those patients who have been shown to be particularly vulnerable to these arrhythmias.

\section{References}

1 Corone P, Doyon F, Gaudeau S, et al. Natural history of ventricular septal defect: a study involving 790 cases. Circulation 1977; 55: 908-15.

2 Allen HD, Anderson RC, Noren GR, Moller JH. Postoperative follow-up of patients with ventricular septal defect. Circulation 1974; 50: 465-71.

3 Weidman WH, Blount SG Jr, DuShane JW, Gersony WM, Hayes CJ, Nadas AS. Clinical course in ventricular septal defect. Circulation 1977; 56, suppl 1: I-56-I-69.

4 Sigmann JM, Perry BL, Behrendt DM, Stern AM, Kirsh, MM, Sloan HE. Ventricular septal defect: results after repair in infancy. Am $\mathcal{F}$ Cardiol 1977; 39: 66-71.

5 Ziady GM, Hallidie-Smith KA, Goodwin JF. Conduction disturbances after surgical closure of ventricular septal defects. Br Heart F 1972; 34; 1199-204.

6 Kulbertus HE, Coyne JJ, Hallidie-Smith KA. Conduction disturbances before and after closure of ventricular septal defect. Am Heart f 1969; 77: 123-31.
7 Yabek, SM, Jarmakani JM, Roberts NK. Diagnosis of trifascicular damage following tetralogy of Fallot and ventricular septal defect repair. Circulation 1977; 55: 23-7.

8 Clark DS, Hirsch HD, Tamer DM, Gelband H. Electrocardiographic changes following surgical treatment of congenital cardiac malformations. Prog Cardiovasc Dis 1975; 17: 451-65.

9 Hobbins SM, Izukawa T, Radford DJ, Williams WG, Trusler GA. Conduction disturbances after surgical correction of ventricular septal defect by the atrial approach. Br Heart f 1978; 41: 289-93.

10 Downing JW Jr, Kaplan S, Bove KE. Postsurgical lef anterior hemiblock and right bundle-branch block. Br Heart F 1972; 34: 263-70.

11 Godman MJ, Roberts NK, Izukawa T. Late postoperative conduction disturbances after repair of ventricular septal defect and tetralogy of Fallot. Circulation 1974; 49: 214-21.

12 Hallidie-Smith KA, Hollman A, Cleland WP, Bental HH, Goodwin JF. Effects of surgical closure of ventricular septal defects upon pulmonary vascular disease. Br Heart f 1969; 31: 246-60.

13 Hallidie-Smith KA, Wilson RSE, Hart A, Zeidifard E. Functional status of patients with large ventricular septal defect and pulmonary vascular disease 6 to 16 years after surgical closure of their defect in childhood. Br Heart $\mathcal{F}$ 1977; 39: 1093-101.

14 Vogel JHK, Grover FR, Jamieson G, Blount SG. Long term physiologic observations in patients with ventricular septal defect and increased pulmonary vascular resistance. Adv Cardiol 1974; 11: 108-22.

15 Weidman WH, DuShane JW. Course of pulmonary hypertension following surgical closure of ventricular septal defect. Adv Cardiol 1974; 11: 131-4.

16 Maron BJ, Redwood DR, Hirshfeld JW Jr, Goldstein RE, Morrow AG, Epstein SE. Postoperative assessment of patients with ventricular septal defect and pulmonary hypertension. Response to intense upright exercise. Circulation 1973; 48: 864-74.

17 Ryan M, Lown B, Horn H. Comparison of ventricular ectopic activity during 24 hour monitoring and exercise testing in patients with coronary heart disease. $N$ Engl f Med 1975; 292: 224-9.

18 Bruce RA. Exercise testing of patients coronary heart disease principles and normal standards for evaluation. Ann Clin Res 1981; 3: 323-32.

19 Antman E, Graboys TB, Lown B. Continuous monitoring for ventricular arrhythmias during exercise tests. FAMA 1979; 241: 2802-5.

20 Okoroma EO, Guller B, Maloney JD, Weidman WH. Etiology of right bundle-branch block pattern after surgical closure of ventricular septal defects. Am Hean $\mathcal{J}$ 1975; 90: 14-8.

21 Rein JG, Freed MD, Norwood WI, Castaneda AR. Early and late results of closure of ventricular septal defect in infancy. Ann Thorac Surg 1977; 24: 19-26.

22 Quattlebaum TG, Varghese PJ, Neill CA, Donahoo JS. Sudden death among postoperative patients with tetralogy of Fallot: a follow-up study of 251 patients for an average of twelve years (abstract). Am $\mathcal{F}$ Cardiol 1975; 35: 164 . 
23 Bristow JD, Kassebaum DG, Starr A, Griswold HE. Observations on the occurrence of right bundle-branch block following open repair of ventricular septal defects. Circulation 1960; 22: 896-900.

24 Wolff GS, Rowland TW, Ellison RC. Surgically induced right bundle-branch block with left anterior hemiblock: an ominous sign in postoperative tetralogy of Fallot. Circulation 1970; 46: 587-94.

25 Goggini CJ, Wareham EE, Selvester RH. Postventriculotomy right bundle-branch block: its etiology (abstract). Circulation 1960; 22: 734.

26 Gelband H, Waldo AL, Kaiser GA, Bowman FO Jr, Malm JR, Hoffman BF. Etiology of right bundle-branch block in patients undergoing total correction of tetralogy of Fallot. Circulation 1971; 44: 1022-33.

27 Lev M, Fell EH, Arcilla R, Weinberg MH. Surgical injury to the conduction system in ventricular septal defects. Am F Cardiol 1964; 14: 464-76.

28 Horowitz LN, Simson MB, Spear JF, et al. The mechanism of apparent right bundle-branch block after transatrial repair of tetralogy of Fallot. Circulation 1979; 59: 1241-52.

29 James FW, Kaplan S, Chou TC. Unexpected cardiac arrest in patients after surgical correction of tetralogy of Fallot. Circulation 52: 691-5.
30 Rosing DR, Borer JS, Kent KM, et al. Long term haemodynamic and electrocardiographic assessment following operative repair of tetralogy of Fallot. Circulation 1978; 58, suppl I: 209-17.

31 Deanfield JF, McKenna WJ, Hallidie-Smith KA. Detection of late arrhythmia and conduction disturbance after correction of tetralogy of Fallot. Br Heart $\mathcal{F}$ 1980; 44: 248-53.

32 Brodsky M, Wu D, Denes P, Kanakis C, Rosen KM. Arrhythmias documented by 24 hour continuous electrocardiographic monitoring in 50 male medical students without apparent heart disease. Am $\mathcal{F}$ Cardiol 1977; 39: 390-5.

33 Keane JF, Plauth WH, Nadas AS. Ventricular septal defect with aortic regurgitation. Circulation 1977; 56, suppl I: I-72-I-7.

34 Moreno-Cabral RJ, Mamiya RT, Nakamura FF, Brainard SC, McNamara JJ. Ventricular septal defect and aortic insufficiency. $\mathcal{F}$ Thorac Cardiovasc Surg 1977; 73: $358-65$.

Requests for reprints to $\mathrm{Dr} \mathrm{K}$ A Hallidie-Smith, Royal Postgraduate Medical School, Hammersmith Hospital, London W12 0HS. 